\title{
INTERthesis
}

\section{DOS AGENCIAMENTOS DO DESEJO À CRIAÇÃO DE MODOS DE VIDA QUEER CONTRA OS FASCISMOS COTIDIANOS}

From the agency of desire to the creation of queer lifestyles against everyday fascisms

\author{
Roberto Rodrigues \\ Mestre em Performances Culturais \\ Instituto Federal de Goiás, Aparecida de Goiânia, Goiás \\ roberto.rodrigues@ifg.edu.br \\ (1) https://orcid.org/0000-0002-9862-561X
}

A lista completa com informações dos autores está no final do artigo

\section{RESUMO}

O presente trabalho parte de cruzamentos de teorias filosóficas que instauram um processo de desterritorialização em torno da noção da representação e da repressão do desejo para pensá-lo enquanto produção de subjetividades, como um processo contínuo de fluxos e acoplamentos que permitem aos indivíduos operar e produzir novos modos de vida a partir de uma ética do próprio desejo. O processo de subjetivação acontece, assim, através dos fluxos, do movimento, do corte cultural que desmistifica a relação interdependente e coerente entre ser humano e natureza; sexo e gênero; gênero e sexualidade para reclamar um modo de ser pautado pelo próprio desejo que se torna um devir-máquina, devir-produtivo, processo infinito de constituição e engrenagem de todas as peças dessa maquinaria desejante. A criação de modos de vida queer parece ser, assim, uma possibilidade de enfrentamento aos fascismos cotidianos apresentando-nos novas possibilidades de vida que encontram brechas e fissuras para jogar com a realidade.

PALAVRAS-CHAVE: Desejo. Agenciamento. Multidões queer. Modos de vida queer.

\begin{abstract}
The present work starts from intersections of philosophical theories that establish a process of deterritorialization around the notion of representation and the repression of desire to think it as a production of subjectivities, as a continuous process of flows and couplings that allow individuals to operate and produce new ways of life from an ethic of desire itself. The subjectivation process happens, therefore, through flows, movement, cultural cut that demystifies the interdependent and coherent relationship between human being and nature; sex and gender; gender and sexuality to claim a way of being guided by the very desire that becomes a becoming-machine, becoming-productive, infinite process of constitution and gear of all the pieces of this desiring machinery. The creation of queer ways of life seems, therefore, to be a possibility of confronting everyday fascisms, presenting us with new life possibilities that find gaps and fissures to play with reality. KEYWORDS: Wish. Agency. Queer crowds. Queer ways of life.
\end{abstract}




\section{INTRODUÇÃO}

O presente texto é provocado, inicialmente, pelo pensamento de Gilles Deleuze. Sua escrita performática e turbilhonadora com viés artístico nos instiga a adentrar o universo filosófico que, por hora, acreditava-se restrito ao universo da academia e a um número reduzido de intelectuais, especialistas que compõem territórios herméticos, distantes e desconectados da realidade, do cotidiano.

A filosofia deleuzeana parece estabelecer novas relações com o mundo criando, assim como a arte, novas possibilidades de pensamento, de sensibilidades e, portanto, de vida. Ao criar essas novas condições, Deleuze mergulha na própria vida fazendo dela uma forma de expressão, extraindo seus afectos e percecptos produzindo, assim, uma filosofia à altura do cotidiano, da própria vida e de nós, sujeitos comuns. Essa aproximação da filosofia com a nossa concretude pode provocar uma espécie de encontro, de arrebatamento, a fim de tornar a própria filosofia um modo de produzir a realidade, de criar e fabricar conceitos em torno dela. Eis, aqui, o desafio desejoso e delirante desta escrita: pensar a realidade, ou melhor, realidades, vidas, sob a ótica da criação, do desejo como produção de modos de vida ${ }^{1}$.

Sob a ótica deleuzeana, em seus escritos, principalmente em parceria com Félix Guatarri na obra O anti-Édipo: capitalismo e esquizofrenia (2010), pretendo discutir a questão do desejo visualizando algumas incursões na obra do filósofo que serão atravessadas por pensadores como Nietzsche e Michel Foucault para refletir sobre processos de subjetivação que buscam, de algum modo, criar e expressar novas formas de existência que encontram brechas e fissuras na realidade.

De que forma podemos refletir sobre o desejo, a partir da constituição de modos de vida desejantes que criam linhas de fuga, que se produzem a partir de estratégias e nos permitem escapar dos fascismos cotidianos, inspirado na visão foucaultiana em " $O$ antiÉdipo: uma introdução à vida não fascista", mas que se deparam, também, com as contradições de uma sociedade capitalista que permite, ao mesmo tempo, que se produzam processos de subjetivação pautados nas singularidades, nos devires, nos delírios criativos

\footnotetext{
${ }^{1} \mathrm{O}$ termo é, aqui, utilizado no sentido deleuzeano apresentando-se como um caminho, como uma saída que nos permite pensar a "subjetividade" numa outra perspectiva: não mais como idealização, como forma. Diferente disso, ela torna-se produção ativa, composição de forças, nomadismo. A geração de "subjetividades" não consiste na delimitação de um "eu", enclausurado e interior. Trata-se, portanto, da criação, da produção de modos singulares de efetivação da relação com o mundo. Chega-se, assim, aos modos de vida.
} 
que podem proporcionar uma certa autonomia dos sujeitos mas que, por outro lado, controla, normatiza e castra os sujeitos no que tange à constituição de seus próprios meios de existência?

A criação de tais estratégias enreda-se, aqui, a partir da visão nietzschiana da vida como obra de arte, mas que se cruza, também, com novos modos de compreender a questão da sexualidade a partir da desconstrução dos paradigmas biológicos e culturais em busca de movimentos maquínicos, uma espécie de filosofia à marteladas empreendida a partir da noção de multidões e modos de vida queer. O queer é entendido, aqui, como um lugar de fricção em que as existências não esperam ser toleradas, nem admitidas. Se trata, assim, das possibilidades de produção dos desejos e suas múltiplas formas.

Destaca-se que o recorte do presente trabalho se direciona às experiências no universo da homossexualidade masculina compreendidas a partir da ótica do desejo no sentido deleuzeano. Trata-se, contudo, de um lugar de fala que não desconsidera outras singularidades ou grupos dissidentes da norma dentro dos movimentos LGBTQI+. Portanto, permeia algumas das possibilidades de construção de modos de vida queer, a partir de existências homossexuais masculinas, dentre outras, que podem ser refletidas nesse contexto.

\section{AGENCIAMENTOS DO DESEJO}

Em Deleuze e Guattari (1992) encontramos a noção da realidade como pura produção, composta por singularidades e sustentada pelo desejo, assim, o desejo, aqui, é produtor de realidades. O desejo cria a possibilidade de produção, criação, invenção de modos e formas de pensamento e, portanto, de vida. Ele é a força motriz que impulsiona a máquina subjetiva, ou seja, que impulsiona o ser humano a produzir, a imergir num devir criador e impulsiona as subjetividades em múltiplas direções, em diversos fluxos, atravessando fronteiras, conectando e desconectando-se, constantemente, constituindo territórios existenciais nômades que podem potencialmente servir como linhas de fuga aos aprisionamentos da grande máquina social. Tudo o que existe é assim produzido.

Essa concepção de desejo provoca a questão dos agenciamentos invertendo a ideia que circula desde Platão do desejo como falta. Desenvolve uma concepção do desejo completamente inversa ao senso comum, à filosofia idealista, ao cristianismo e à psicanálise. O desejo não é falta, é produção. Pelo fato de ser fluido, atravessa com sua 
potência criativa os meios sociais na invenção do novo e na produção de intensidades. Dessa forma, divergindo da concepção psicanalítica, o desejo não é uma falta, e sim uma criação de vida, o desejo não carece de nada.

O desejo sempre foi para Deleuze uma espécie de construtivismo, como afirma o filósofo na entrevista intitulada O abecedário de Gilles Deleuze (1988). Desejar é construir um agenciamento, construir um conjunto, construir uma região, é realmente agenciar.

Então algo se passa, um raio passa, ou não, um riachinho... É do campo do desejo. Mas um desejo é isso, é construir. Ora, cada um de nós passa seu tempo construindo, cada vez que alguém diz: desejo isso, quer dizer que ele está construindo um agenciamento, nada mais, o desejo não é nada mais (DELEUZE, 1988, p.19).

É nesse sentido da produção, do agenciamento, da criação de um campo de forças do desejo que Deleuze e Guattari vão construir, em conjunto, a noção de desejo pela qual percorre este estudo. Através de uma inversão, Deleuze e Guattari atacam certo idealismo psicanalítico que reduz o desejo e toda sua produção desejante a um sistema de representações ditas inconscientes e ao modelo pautado na lei, na falta e na negatividade. A introdução da figura de Édipo no campo da psicanálise talvez seja uma dessas formas de representação e de repressão dos desejos e da libido no contexto da instituição familiar. Essa tradição de pensamento demarca fundamentalmente um aparelho manipulado pelas forças de opressão e repressão (DELEUZE e GUATTARI, 2010) que para os autores ameaçam todo e qualquer movimento revolucionário que se faça em prol de uma política, uma ética e estética do desejo, da produção desejante, do desejo como criação.

Chamamos idealismo da psicanálise todo um sistema de rebatimentos, de reduções na teoria e prática analíticas: redução da produção desejante a um sistema de representações ditas inconscientes, e as formas de causação de expressão e compreensão correspondentes; redução das fábricas do inconsciente a uma cena de teatro, Édipo, Hamlet (...). A psicanálise não faz mais do que elevar Édipo ao quadrado, Édipo de transferência, Édipo de Édipo, no divã como uma terrinha lamacenta. Porém familiar ou analítico, o Édipo é fundamentalmente um aparelho de repressão das máquinas desejantes (DELEUZE e GUATTARI, 1992, p.27-28).

Propondo-se a uma esquizoanálise, as críticas de Deleuze e Guattari tomam a questão do desejo em oposição à psicanálise em pontos onde ela tropeça: "não consegue atingir as máquinas desejantes de ninguém, porque se limita às figuras ou estruturas edipianas; não chega aos investimentos sociais da libido, porque se restringe aos 
investimentos familiares" (DELEUZE e GUATTARI, 1992, p.32). Daí o fato de que esse outro modo de pensar opera uma forma de criação que escapa aos códigos e nos permite liberar fluxos, movimentos, linhas de fuga que se afirmam em novos modos de vida que se opõem e ultrapassam os limites da sociedade e da cultura.

Essa concepção de desejo vai contra a psicanálise, que o preconiza como algo recalcado e reprimido, proveniente do inconsciente que, por sua vez, é dominado pela tríade Pai-Mãe-Filho, o complexo de Édipo e a castração. Deleuze e Guattari não ignoram a noção de inconsciente, mas o entendem em uma dimensão diferente do inconsciente freudiano, provocando a ideia de um inconsciente maquínico. Propõem-no como fabricação, como contínua produção.

Admite-se que a grande descoberta da psicanálise foi a da produção desejante e das produções do inconsciente. Entretanto, a crítica feita pelos filósofos é de que com a descoberta de Édipo, substituiu-se o inconsciente como fábrica por um teatro antigo. Assim, a noção da representação do inconsciente passou a imperar como forma a ser interpretada em toda a sua extensão. Com isso, o desejo passa a ser produzido como uma realidade psíquica, proveniente do inconsciente dos indivíduos e pautado, ainda, na essência da "falta". Desta forma, o desejo estará diretamente relacionado ao sonho, ao fantasma de um objeto inatingível, aquilo que falta.

Isso significa que o objeto que falta ao desejo remete a algo natural e extrínseco ao ser. Portanto, quando se deseja, deseja sempre algo, um objeto externo e, por sua vez, ligado à satisfação de necessidades produzidas nessa sua relação de falta com o objeto. Desta forma, o desejo estaria fora do indivíduo que deseja. Disso deriva uma forma de desejo idealista, pois o mundo "não contém todos os objetos, falta-lhe pelo menos um, o do desejo; logo, existe um objeto, alhures, que contém a chave do desejo (um, que falta ao mundo)" (DELEUZE e GUATTARI, 2010, p.43)

No livro $O$ anti-Édipo capitalismo e esquizofrenia Deleuze e Guattari desterritorializam a noção da representação e da repressão do desejo para pensá-lo enquanto produção de subjetividades, como um processo contínuo de fluxos e acoplamentos que permitem aos indivíduos operar e se produzirem a partir de uma ética do próprio desejo. O processo de subjetivação acontece, assim, através dos fluxos, do movimento, do corte cultural que desmistifica a relação interdependente e coerente entre ser humano e natureza; sexo e gênero; gênero e sexualidade para reclamar um modo de ser pautado pelo próprio desejo que se torna um devir-máquina, devir-produtivo, processo infinito de constituição e engrenagem de todas as peças dessa maquinaria desejante. 
Cada um de nós compõe máquina, uma construção subjetiva e particular que irrompe um nível de potência em constante devir, expansão e contração. Ao se acoplarem as máquinas constituem um conjunto, e este é fruto e condição para o desejo. Arranjos, agenciamentos, composição, construção. É esta a fórmula de Deleuze: o desejo corre dentro de um agenciamento, de uma síntese, da produção.

É assim que todos somos "bricoleurs", cada um com as suas pequenas máquinas. Uma máquina-órgão para uma máquina-energia, sempre fluxos e cortes. (...) Tudo compõe máquina. Já não há nem homem, nem natureza, mas unicamente um processo que os produz um no outro e acopla as máquinas. Há em toda parte máquinas produtoras ou desejantes. (...) O desejo não para de efetuar o acoplamento de fluxos contínuos. (...) O desejo faz correr, fluir e corta (DELEUZE e GUATTARI, 2010, p.12, 16).

O desejo é máquina, síntese de conexões maquínicas que se produzem no próprio produzir, nos fluxos, nos movimentos conectivos que não cessam de acoplarem-se, de produzir efeitos e não produtos. O que há nessas territorialidades desejosas são sempre intensidades, campos de força, energias, pulsões. Se entendemos, como Deleuze, que o desejo é o desejo de um conjunto, então é o próprio sujeito do desejo que agencia os elementos que os arranjam e rearranjam.

Desejar é uma produção maquínica, é construir um agenciamento, construir um conjunto, uma paisagem desejante. Somos máquinas desejantes. Desejamos e produzimos nossas realidades a partir dos próprios desejos. Portanto, o processo de subjetivação se enreda pelo agenciamento dos desejos e a construção das identidades que serão sempre provisórias, cambiantes e contingentes. São processos circunstanciais que se agenciam constantemente em criações, invenções de si e todas as possibilidades de refazer-se. A criação é desejo em potencial, pois desejamos a vida, desejamos fazer da própria vida processos e não produtos.

O desejo aqui não é algo apoiado nas necessidades, objeto externo, irreal. São as necessidades, produtos do próprio desejo. $O$ desejo é produção, produz o próprio indivíduo como ser desejante. O desejo é um processo de conexões, de acoplamentos de fluxos e corpos que funcionam como uma maquinaria. Máquinas acopladas a outras máquinas que formam uma unidade desejante. Por isso a coletividade aqui é máquina. São ajuntamentos de peças, motores potenciais, modos de subjetivação que se acoplam e formam um todo desejante. $O$ desejo produz as máquinas que por sua vez são processos de produção em si, desejantes. 
O desejo e o seu objeto constituem uma só e mesma coisa: a máquina, enquanto máquina de máquina. O desejo é máquina, o objeto do desejo é também máquina conectada, de modo que o produto é extraído do produzir e algo se destaca do produzir passando ao produto e dando um resto ao sujeito nômade e vagabundo (DELEUZE e GUATTARI, 2010, p.47).

O desejo, portanto, deseja o real, a produção de máquinas desejantes que não se separam do próprio desejo. O desejo é devir, é produção de produções, é o constante fluxo pelo qual se deseja e se produz os processos de subjetivação. Assim, cada máquina funciona do seu modo, operando através dos desejos e das conexões maquínicas que se acoplam na estrutura da própria máquina. Por isso o desejo produz máquinas diferenciais, diversas, diferentes entre si.

O processo opera sempre em rupturas, os agenciamentos de desejo se efetuam como intrusão, fora de uma relação fictícia do eu, substituindo-o por uma relação com o demoníaco na natureza (DELEUZE e GUATTARI, 2010). As produções do desejo ressoam da união, da conexão, dos fluxos que atravessam as estruturas de cada máquina, produzindo sempre linhas de fuga que desafiam e enfrentam todo tipo de identificação, de construção de personalidades dadas a priori, fixadas nos limites do eu ou qualquer modelo estrutural gerativo.

Cada máquina é um processo que se desarranja a partir de seus inúmeros acoplamentos e conexões. As máquinas são desarranjos, pois estão em constantes processos de subjetivação. Diferente da máquina social, que não funciona se estiver desarranjada, as máquinas desejantes são em si desarranjos, multiplicidades, curtocircuitos de fluxos e movimentos infinitos (DELEUZE e GUATARRI, 2010).

Os agenciamentos do desejo, as multiplicidades e toda essa maquinaria de guerra em Deleuze e Guattari (2010) são pensados como plano de imanência, como produção ativa que não cessa de se produzir constantemente. $O$ desejo nunca é falta, nem carência, pelo contrário, é a própria potência, a produção de subjetivação, a criação do próprio agente desejante. Somos todos desejos em potencial. Somos fluxos constantes. Fervilhamentos. Intensidades.

Cada máquina é um objeto parcial que interpreta e olha o mundo ao seu redor segundo seu próprio fluxo. Mas as máquinas se acoplam, conectam-se produzindo fluxos que se cruzam, misturam, numa espécie de movimento infinito. O desejo é um agenciamento, é o ato de arranjar, de compor e de construir (LARRAURI, 2009). Daí a 
incursão deleuzeana sobre as máquinas desejantes, pois o desejo corre dentro dos fluxos, das conexões, da síntese.

O desejo não para de efetuar o acoplamento de fluxos contínuos e de objetos parciais essencialmente fragmentários e fragmentados. O desejo faz correr, flui e corta. "Amo tudo o que flui, mesmo o fluxo menstrual que arrasta os ovos não fecundados...", diz Miller no seu cântico do desejo. Bolsa de água e cálculos do rim; fluxo de cabelo, fluxo de baba, fluxo de esperma, de merda ou de urina produzidos por objetos parciais constantemente cortados por outros objetos parciais que, por sua vez, produzem outros fluxos também recortados por outros objetos parciais (DELEUZE e GUATTARI, 2010, p.16).

Essa forma de encarar e lidar com o desejo abre espaço para que pensemos na questão dos processos de subjetivação, pois os fluxos do desejo são sempre cortados por tantos outros fluxos e, portanto, ao desejar se deseja, inclusive, o desejo do outro. Eis aí uma contradição: ao constituirmos nossos processos, ao criarmos nossas próprias condições de existência, de vida, somos, constantemente, atravessados por outros tantos modos de vida e, portanto, de tantas outras formas de desejo, outros tantos fluxos. Daí o fato de que a sociedade influencia diretamente na maneira como nos produzimos e, certamente, até mesmo, na produção dos nossos desejos.

Ao pensarmos o desejo sempre em conjunto, nas conexões, nos atravessamentos e cortes de fluxos, então somos nós mesmos, sujeitos do desejo, que agenciamos os elementos, que construímos e produzimos nossos fluxos desejantes. Portanto, o desejo está implicado, também, em processos onde somos enganados, incentivados a desejar aquilo que se pode obter através de uma relação de produto. Nesse sentido, essa forma de desejo poderá nos aprisionar, assumindo o risco de perdermos a própria potência do desejo, como possibilidade de construir novas condições para o próprio desejar. "Verdadeiramente difícil é desejar, porque desejar implica a própria construção do desejo: formular o agenciamento que se deseja, que mundo se deseja, para que seja o mundo no qual seu desejo flua" (LARRAURI, 2009, p.82). Eis o desafio que a proposta deleuzeana de encarar o desejo nos propõe: fazer da própria vida uma forma de agenciamento dos desejos, desejar o próprio desejo e, portanto, desejar a própria vida.

Desejar, portanto, tem sua potência, que extrapola os limites daquilo que cada indivíduo naturalmente é capaz de fazer, mas, ao contrário, expande a noção dessa potência para pensar naquilo que de fato é possível criar e o que realmente criamos. Assim, o desejo tem sua potência na própria criação, na invenção de outras possibilidades de 
agenciamento da própria vida. E tal potência só se dá na medida em que formos afetados pelo desejo e, por sua vez, pela vida.

A proposta deleuze-guattariana de contraponto aos fascismos do poder aparecem na medida em que nos provocam a pensar nas linhas de fuga que nos conduzem ao desejo, às maquinas do desejo e à organização de um campo social do desejo: "não se trata de cada um fugir 'pessoalmente', mas de fazer fugir, como quando se arrebenta um cano ou um abcesso"' (DELEUZE; GUATTARI, 1992, p.30). Trata-se, portanto, não somente de lutar individualmente ou tentar criar formas contrárias ao sistema capitalista, mas, sobretudo, de insurgir possibilidades que desloquem, cortem e atravessem o campo social para fazê-lo delirar, fluir e conectar-se às linhas do desejo.

Vemos, aqui, a possibilidade de pensar os processos de subjetivação como meio pelo qual o desejo faz fluir e se produz intensivamente não como algo que falta, mas como potência criativa que, ao mesmo tempo, produz e é produzido no meio social. Portanto, não se trata de controlar, reprimir ou interpretar as formas do desejo, mas sim, de saber como funciona, como no campo social é possível delirar, fluir, conectar através dos fluxos e das máquinas desejantes?

Essa forma de encarar o desejo nos permite visualizar como ele é introduzido no pensamento, no discurso, na ação. Quais seus desdobramentos na esfera política e como ele pode se intensificar no processo de reversão da ordem estabelecida. Dimensões, essas, apontadas por Michel Foucault em um prefácio de $O$ anti-Édipo capitalismo e esquizofrenia, onde apresenta a obra de Deleuze e Guattari dizendo que se trata de um livro de ética que tornou-se um estilo de vida, um modo de pensamento e de vida. O elogio foucaultiano ao O anti-Édipo nos provoca a visualizar a obra como um fluxo desejante, uma aposta produtiva que não cessa de encontrar uma arte de viver contrária a todas as formas de fascismo.

Diríamos inclusive que Deleuze e Guattari gostam tão pouco do poder que buscam neutralizar os efeitos do poder ligados a seu próprio discurso. Donde os jogos e as armadilhas que de algum modo se encontram por toda parte no livro, e que fazem de sua tradução uma verdadeira proeza. Mas não se trata das brincadeiras familiares à retórica, aquelas que buscam seduzir o leitor sem que esteja consciente da manipulação e que terminam por ganhá-lo para a causa dos autores contra a sua vontade. As armadilhas de O anti-Édipo são as do humor: convites a se deixar expulsar, a abandonar o texto batendo a porta. O livro faz pensar com que frequência que só há humor e jogo ali onde entretanto algo de essencial se passa, algo que é da maior seriedade: o banimento de todas as formas de fascismo, desde aquelas, colossais, que nos envolvem e nos esmagam, até as formas 
miúdas que fazem a amarga tirania de nossas vidas cotidianas (FOUCAULT, 1993, p.200).

O anti-Édipo torna-se, nesse sentido, uma espécie de guia da vida cotidiana. A obra, na perspectiva apontada por Foucault, extrapola a dimensão de uma referência teórica, pois deveria ser encarado como arte, criação, invenção de novas possibilidades de enfrentamento, de incursão no cotidiano sob a ótica dos processos de subjetivação, do entendimento dos fluxos, das sínteses, das conexões possíveis a partir da questão do desejo e das máquinas desejantes.

$\mathrm{Na}$ leitura foucaultiana de $\mathrm{O}$ anti-Édipo, um dos princípios apontados contra as formas dos fascismos cotidianos seria a liberação da ação política de toda forma unitária e totalizante. Abre-se a um movimento das multiplicidades ${ }^{2}$. Essa perspectiva abre a possibilidade de pensarmos na criação de estratégias coletivas em que os investimentos econômicos, libidinais e políticos estariam conectados numa espécie de exercício militante articulando os interesses entre as classes. Assim, a ação, o pensamento e os desejos devem crescer por proliferação, justaposição, disjunção e não por subdivisão e hierarquização.

Trata-se de um investimento revolucionário onde se faça cargo do desejo e dos fenômenos do desejo tanto no campo social como no campo do inconsciente conectando seus fluxos e fazendo funcionar uma possível maquinaria coletiva onde se produza por sínteses, por acoplamentos e, não mais, por subdivisões e hierarquias.

Outro princípio apontado por Foucault perpassa pela questão de livrar-se das velhas categorias do negativo: a lei, os limites, as castrações, a falta. A ideia da produção desejante insurge e considera aquilo que é múltiplo, positivo preferindo os fluxos às unidades, os agenciamentos móveis aos sistemas. As produções do desejo estão, assim, mais no campo do nomadismo ${ }^{3}$ do que do sedentarismo.

Um outro princípio é assim descrito por Foucault: "Não imaginem que seja preciso ser triste para ser militante, mesmo se o que se combate é abominável. É a ligação do desejo com a realidade (e não sua fuga nas formas da representação) que possui uma força

\footnotetext{
$2 \mathrm{O}$ conceito de multiplicidade opera como um processo de enfrentamento à noção de unidade, de totalidade e universalidade. As multiplicidades se definem pelo fora, pelas linhas de fuga (DELEUZE e GUATTARI, 1995).

${ }^{3}$ Em referência ao conceito de nomadismo da obra Mil Platôs-vol.5. O nômade como aquele que não tem pontos fixos, nem trajetos previamente estabelecidos. O nômade como o desterritorializado que encontra na própria desterritorialização o seu território. Os territórios nômades são fluidos, desterritorializados e reterritorializados constantemente. O nomadismo opera por movimentos, por desterritorializações.
} 
revolucionária" (FOUCAULT, 1993, p.199). É nesse sentido que propomos, logo adiante, a pensar na força revolucionária da constituição de modos de vida queer como possibilidade de criação de uma nova estratégia de vida. A ligação do desejo com a realidade, com a vida abre brechas para pensarmos nas homossocialidades como um modo de vida desejante e, certamente, com nuances revolucionárias.

Tais princípios nos apontam a dimensão estratégica e potencial da obra de Deleuze e Guattari. Ao encarar essa obra como uma arte diretamente articulada à vida cotidiana, Foucault nos apresenta a filosofia deleuze-guattariana à altura da própria vida. Daí que a dimensão do desejo se torna uma possibilidade de estratégia de vida, pois as análises feitas a partir de $O$ anti-Édipo nos provocam a criar, a inventar novas possibilidades de pensamento e existência a partir delas.

É nesse sentido que buscamos, aqui, pensar os processos de subjetivação, a criação de linhas de fuga como formas de ultrapassar os fascismos cotidianos e de maneira humorada jogar com a própria vida. Olhar a vida sob a ótica da arte e, ao mesmo tempo, encarar a arte como uma possibilidade de vida. Um cruzamento deleuze-nietzschiano provocado pela crítica foucaultiana sob essa forma de encarar e fazer fluir as dimensões do desejo.

Trata-se, portanto, de destacar e realçar algumas das possibilidades de vida que ultrapassam e se desviam do terreno sombrio e hermético dos controles, das normas, das vigílias sociais. Tomar a questão do desejo que não se restringe aos limites dicotômicos empreendidos pela naturalização das relações e sua aparente coerência. É preciso, então, fazer funcionar as máquinas desejantes a partir dos processos de subjetivação para pensarmos o campo dos agenciamentos e da criação de estratégias e linhas de fuga como novas possibilidades de vida, como criação de modos de vida desejantes.

Será possível desterritorializar a noção da representação e da repressão do desejo para pensá-lo enquanto produção de subjetividades a partir de sua potência? Busca-se, a seguir, acompanhar essa potência do desejo sob a ótica da produção de subjetividades a partir da criação do que chamo, aqui, de modos de vida queer. 


\section{PENSANDO A NOÇÃO DE MULTIDÕES QUEER(OPA!) MULTIDÕES CU ${ }^{4}$}

A imagem da multidão nos serve na medida em que faz pensar e agir sobre o desejo, seus fluxos, seus agenciamentos maquínicos como uma forma de "enrabar" a heteronormatividade ${ }^{5}$, de fecundá-la pelas costas, utilizando novamente a expressão de Deleuze e Guattari (2010). Esse processo de enrabada é concebido, aqui, como um movimento produtivo e desejoso onde o enrabar gera prazer e deleite ao desterritorializar as convenções e normas impostas às formas de sociabilidade entre os homossexuais. Desviando-se do campo da discursividade que regula e pune os indivíduos, da nomeação e das categorias fixas, a homossexualidade no contexto das multidões aponta para uma transvaloração dos sentidos convencionais referentes a esses modos de vida queer.

Questionando as teorias e reivindicações de acolhida à diferença que têm como traço fundamental a separação e a categorização dos indivíduos a partir de identidades previamente estabelecidas como "mulher", "gay", "lésbica" advindas de uma base natural para legitimá-los, a ideia das multidões queer, termo empregado por Paul Preciado no artigo Multidões queer: notas para uma política dos 'anormais', publicado na Revista Estudos Feministas (2011) empreende outro tipo de esforço político ao recusar a existência dessas identidades e transformar as minorias, os excluídos, os "maus sujeitos" em potenciais de resistência e desvio à norma.

Preciado reivindica um movimento pós-feminista ao lado de nomes como Teresa de Lauretis, Donna Haraway, Judith Butler, Jack Halberstam, para citar alguns desse movimento de confronto com o feminismo clássico que vem rejeitar a "noção de feminilidade

\footnotetext{
${ }^{4}$ Lembrando as "teorias do cu" em obras como Homossexualidade molecular (ou) da filosofia como modo superior de dar o cu no Manifesto Contrassexual de Paul Preciado (2014); "Terror Anal"- Paul Preciado (2009); em Gilles Deleuze e Félix Guattari (2010) no O Anti-Édipo. Ao se debruçar no platô Deleuze-Preciado, Petronilio (2015a) salienta que Preciado mostrou junto com Deleuze a forma viva de ativar o pensamento e enrabar a representação. Petronilio ainda argumenta que duas obras de Deleuze afetaram diretamente Preciado: O Anti Édipo, onde a partir daí, Preciado faz críticas junto com Deleuze à Psicanálise e Proust e os signos, frutos desse pathos onde, mais uma vez, junto com Deleuze, ele dá um lugar privilegiado ao homossexual, esse lugar filosófico, como bem trouxe René Schérer. Herança, certamente, de Nietzsche, "Gaia-ciência" em seu Gay-saber, saber alegre, saber gay. O último ensaio do Manifesto Contrassexual de Preciado, Da filosofia como modo superior de dar o cu, segundo Petronilio, é um giro na Diferença Deleuzoguattariana, uma forma de arrombar o fascismo e potencializar um ethos da alegria. Desse modo, ainda acrescenta Petronilio, a Filosofia passa a ter a sua gênese no ato de enrabar e violentar o pensamento, pegálo por trás, pelo cu. Preciado diz "os filósofos anais da história estão ligados pelo fluxo textual de uma margarida que une o ânus e os pintos, que interpreta e traduz. A Filosofia é, portanto, uma forma de inseminação artificial por meio do qual o ânus semiológico vem a ser útero (mulher) e mais tarde inseto polinizador (animal), e assim uma e outra vez, incessantemente (PRECIADO, 2014, p. 193).

${ }^{5} \mathrm{O}$ termo heteronormatividade aparece, aqui, como marcador do conjunto de práticas discursivas que regulam, distinguem e naturalizam a heterossexualidade como única prática sexual aceita. $\mathrm{O}$ termo é recorrente nos estudos de Guacira Lopes Louro.
} 
que havia sido, inicialmente, a fonte de coesão do sujeito do feminismo" (PRECIADO, 2011, p.17). Essas críticas delinearam a recusa em naturalizar e traçar uma essência para o sujeito político "mulher" hegemônico e heterocêntrico.

Ao lado dessas críticas pós-feministas houve a reação das minorias homossexuais representadas por gays, lésbicas, transexuais, transgêneros para questionar "a validade da noção de identidade sexual como único fundamento da ação política e para opor uma proliferação de diferenças (de raça, de classe, de práticas sexuais não normativas)" (PRECIADO, 2011, p.18). Buscam desviar-se dos efeitos normativos e disciplinares das formações identitárias que naturalizam as diferenças tornando-as os únicos focos da ação política. A noção de multidão queer ousa e rompe com a ideia de "diferença sexual" explorada pelo feminismo clássico como, também, pelas variações estruturalistas do discurso da psicanálise.

Essa corrente de pensamento se constitui em torno da noção de queer, termo utilizado pela primeira vez por Teresa de Laurettis em 1990, e da teoria queerque, segundo Richard Miskolci (2007), foi utilizada pela primeira vez "para contrastar o empreendimento analítico que um conjunto de pesquisadores desenvolvia em oposição crítica aos estudos sociológicos sobre minorias sexuais e de gênero" (MISKOLCI, 2007, p.2). O queer designa a diferença que não aspira o centro, que não quer ser assimilada ou tolerada e que, portanto, pode constituir uma forma de ação transgressiva e perturbadora (LOURO, 2000). Tais autores contornam o termo queer que parece ser uma denominação aberta, em constante processo que abrange tanto as correntes teóricas quantos os movimentos sociais contemporâneos que lutam em defesa das culturas sexuais marginalizadas.

Guacira Lopes Louro no livro O corpo educado problematiza a conceituação e a divisão das práticas sexuais na história discutindo a questão do surgimento de termos que passaram a categorizar e funcionar como uma espécie de dispositivo histórico para controlar e vigiar a vida sexual dos indivíduos. A institucionalização da heterossexualidade é uma das formas pela qual esse controle foi amplamente exercido irrompendo numa compulsão discursiva que a define como única forma aceitável condenando quaisquer outros tipos de atividades sexuais. Assim, a heterossexualidade passa a servir como norma e como objeto de distinção social.

Essa institucionalização nos séculos XIX e XX foi um elemento importante de controle social ao lado da definição da homossexualidade como forma de "anormalidade", prática tida como perversão. Assim, a categorização e a divisão entre o "normal" e o "anormal" passou a legitimar a questão da diferença a partir de discursos e práticas 
segregacionistas. Essas categorias foram frutos do empreendimento médico para definir as características básicas do que constitui a masculinidade e a feminilidade normais, vistas como características distintas dos homens e das mulheres; e da legitimação das hierarquias onde as práticas sexuais poderiam ser distinguidas.

Em contrapartida a essa institucionalização, os estudos constituídos a partir da teoria queer possibilitaram a ampliação e deslocamentos dos olhares em torno da construção das identidades sexuais para compreender de que forma os processos sociais regulatórios e normativos criam classificações, as quais, por sua vez, geram a ilusão de sujeitos estáveis, identidades sociais e comportamentos coerentes e regulares. Assim, a partir de novos olhares pôde-se investigar a multiplicidade de formas com que os indivíduos experimentam e agenciam suas sexualidades.

As práticas corporais que envolvem, dentre outros aspectos, a maneira como os indivíduos se vestem, agem corporalmente, relacionam-se com outros indivíduos desafiam constantemente a coerência e as regras impostas pelo padrão heterossexual. A construção das identidades de gênero e da orientação sexual das multidões queer, termos recorrentes para designar a forma como os indivíduos experimentam sua sexualidade e suas existências, vêm sendo agenciadas a partir do desvio da normalização dessas relações, buscando "mostrar como os 'fundamentos' ou 'substâncias', aquilo que é tido como 'natural', é sempre um efeito de práticas discursivas culturalmente dadas, que operam (...) dentro de matrizes de poder" (BRAZ, 2014, p.59).

Nesse sentido, as multidões queer surgem como provocação à heteronormatividade que produz discursivamente formas de identificação e normalização das relações entre o sexo, o gênero e a sexualidade. O termo queer se constitui de forma indeterminada e elástica focando na incompatibilidade entre essas três categorias (sexo, gênero e sexualidade). Trata-se, portanto, de pensar as várias dimensões que envolvem a produção dos corpos e suas sexualidades para além das características biológicas e naturais dos indivíduos. Os corpos, seus prazeres, desejos e suas sexualidades são contingentes e modificáveis a partir do contexto social, histórico e cultural no qual estão inseridos, estando interseccionados com outros marcadores como cor, raça, nacionalidade, idade, etc.

Trata-se, então, tanto de desconstruir ${ }^{6}$ as categorias analíticas que operam por dicotomias e binarismos como pensar nas múltiplas possibilidades de agenciamento pelas

\footnotetext{
${ }^{6}$ Petronilio (2014) afirma que é importante levar a sério essa categoria da desconstrução para os estudos de gênero, pois reconhece que Derrida (2013), e talvez uma das contribuições do pensador da desconstrução para o pensamento da Diferença, está situada em sua Gramatologia, especificamente a noção de suplemento
} 
quais os corpos se materializam e produzem suas subjetividades sempre de forma contingente e contextual. Os modos de vida queer são produzidos, então, de inúmeras formas, por seus diferentes agentes constituindo seus bandos, multidões, aglomerados.

O termo queer é agenciado e assumido como forma de oposição e contestação. Forma de se colocar contra as normatividades, sejam elas vindas das categorias classificatórias de sexo, raça, gênero, enfim, contra todo tipo de classificação normativa. Assim, se assumir numa condição queer é desviar-se do centro, das universalidades, das identidades previamente estabelecidas.

Esse termo, com toda sua carga de estranheza e de deboche, é assumido por uma vertente dos movimentos homossexuais precisamente para caracterizar sua perspectiva de oposição e contestação. Para esse grupo, queer significa colocar-se contra a normalização- venha ela de onde vier. Queer representa claramente a diferença que não ser que assimilada ou tolerada e, portanto, sua forma de ação é muito transgressiva e perturbadora (LOURO, 2008, p.38-39).

É nesse terreno da oposição, do enfrentamento e da contestação que abrimos a possibilidade para pensar territórios onde se constituem esses modos de vida que não esperam ser tolerados, aceitos e, muito menos, agir dentro do que espera a sociedade heteronormativa que vigia e controla todos os tipos de prazeres e desejos sexuais. Dentre as oposições e os enfrentamentos talvez a questão da heterossexualidade como norma seja seu maior alvo. Escapar da norma e abrir-se às possibilidades de autodeterminação de agência. Pensamos assim na condição abjeta, nômade, marginal desses modos de vida que se abrem às multiplicidades, ao diverso e aos agenciamentos que aí operam.

Os modos de vida das multidões queer podem funcionar, então, não apenas como um modo de existir, de ser e transitar pelos espaços sociais, mas trata-se, antes, de posicionamentos, de modos de enfrentar as formas instituídas de saberes e poderes que regulam e normatizam nossas vidas e, portanto, nossas sexualidades. Abre-se, assim, a possibilidade de produzir políticas que poderiam ser chamadas de políticas queer se a potência de resistir continuar a reinventar outros/novos modos de vida (LIMA, 2014).

As reflexões de Fátima Lima (2014) são importantes na medida em que assinala a condição necessária para a produção desses novos modos de vida na emergência de

ou suplementaridade, quando o autor fala "este perigoso suplemento...". Trata-se de um conceito fundamental para colocar em xeque os binarismos e ao mesmo tempo colocar a representação em crise. A metafísica da presença, a metafísica da substância e a diferença ontológica entre ser e ente que perpetuou ao longo de uma tradição que vai do grego à Heidegger, é colocada em crise. Dois livros fundamentais: $A$ escritura e a diferença (2003) e a Gramatologia (2013) nessa “onda contrassexual”. 
possíveis estratégias políticas e, portanto, éticas e estéticas na constituição de processos que desconstroem as identidades sexuais normalizadas social e culturamente, desterritorializando a heterossexualidade como norma. Assim, a produção dessas políticas se delineia na potência da coletividade em um movimento conectivo que se agencia a partir do diálogo entre transgressão, políticas queer e os modos de vida constituídos pelas multidões.

Tratamos de rastrear esses agenciamentos que possibilitam desestabilizar, deslocar, denunciar e, sobretudo, criar outras possibilidades de viver e pensar as homossocialidades como ferramentas da grande maquinaria produtiva que faz pulsar e fluir os desejos e prazeres como fontes fundamentais da vida. A sexualidade, as relações, os atos corporais são, todos eles, peças maquínicas que podem funcionar como forma de resistência e contestação aos modos de vida produzidos pelo discurso compulsivo da heterossexualidade.

A questão homossexual abordada por René Schérer (1999) em Deleuze e a questão homossexual- uma via não platônica da verdade inspira o filósofo e se torna um signo transformado em objeto de pensamento, fazendo da própria homossexualidade uma condição de pensamento sobre a vida. Ela dá o que pensar ao expor suas multiplicidades, suas redes, produzindo uma complexa forma de existência se afastando, assim, do caminho da verdade comum, das verdades universais fazendo brotar a concretude desses novos modos de vida.

A homossexualidade é retirada, então, do campo da vergonha, da culpabilidade para ser pensada em sua condição perversa, como modo de criação, de invenção de novas formas de pensar, agir e, portanto, de viver. Assim como a filosofia nietzschiana que opera a marteladas criando novas condições para o pensamento, a homossexualidade se afirma perversamente ao torcer, ao curvar seu plano de imanência irrompendo uma sexualidade de outra natureza, outra perspectiva sobre a questão sexual. Homossexualidade e filosofia tornam-se, portanto, fluxos de uma mesma síntese conectiva e perversa.

A perversão, liberada de qualquer referência normativa, moralizante, e não designando nada mais que o voo livre dos afetos, livre dos pesos freudianos (as profundidades), liga-se com o pensamento inventivo (...). Ela mantém com o pensamento inventivo uma relação privilegiada. Em um paralelismo surpreendente, em uma correspondência termo a termo, pensamento e homossexualidade se respondem. O pensamento platônico é comandado pela hierarquia do logos, e sua pederastia é, igualmente, anagógica, ascencional. O pensamento cínico, estoico, epicurista, nietzschiano- em 
uma palavra, moderno- ao afastar-se desse logos, é perverso, e a homossexualidade é o paradigma da perversão (SCHÉRER, 1999, p.145).

Nesse sentido, pensamos à maneira de Deleuze na homossexualidade como uma outra via de experiência da sexualidade que requer, também, outras maneiras de operar com o pensamento, pois ao colocar a questão homossexual como um objeto do pensamento se criam novas exigências para o pensar, novas palavras, novos termos para lidar com essa outra condição de vida. Daí sua perversidade que se aproxima do pensamento filosófico nietzschiano ao afastar-se da hierarquia da razão, da verdade, dos dogmatismos e abre-se à criação de novas formas de pensamento. A filosofia pensada, então, nos mesmos termos dessa homossexualidade perversa.

Ainda operando nesse movimento, trazemos a noção da homossexualidade molecular em Deleuze e Guattari (2010) ao engajarem-se na análise da sexualidade a partir dos fluxos do desejo e de sua composição molecular. Para os autores ela só pode ser pensada como um fluxo entre outros estando em conjunção com outros fluxos. Assim o movimento, a conexão, a síntese produtiva dos fluxos de desejos é o que faz de todos nós "homossexuais pessoalmente, sabendo ou não, e enfim, transexuais molecularmente" (DELEUZE \& GUATTARI apud SCHÉRER, 1999, p.135) ultrapassando a visão platônica do ser e não ser.

Longe de se fechar sobre "o mesmo", a homossexualidade vai se abrir para todas as novas relações possíveis, micrológicas ou micropsíquicas, essencialmente reversíveis, transversais com tantos sexos quantos forem os arranjos... Não se trata mais de ser nem homem, nem mulher, mas de inventar sexos, assim como um homossexual homem pode encontrar em uma mulher os prazeres que um homem lhe daria e inversamente (DELEUZE apud SCHÉRER, 1999, p.152).

Nesse sentido, a homossexualidade é vista como uma multiplicidade que inclui todos os tipos de transversalidades, de movimentos maquínicos que operam por fluxos que desterritorializam as verdades universais e as formas de pensamento e de vida subjugadas aos valores e normas da sociedade. É assim que todos podemos ser homossexuais na perspectiva aqui apontada. Não se trata da questão sexual em si, mas, antes, de um movimento filosófico em torno da própria vida. Devir-homossexual, devir-molecular. É assim que poderemos criar novas estratégias, novos modos de vida inventados, fabricados e transformados, constantemente, sob outros e novos signos de vida e de pensamento. 


\section{CONSIDERAÇÕES FINAIS}

A questão do desejo colocada sob a ótica deleuzeana desterritorializa a noção do desejo como falta para pensar o desejo como produção, como criação. A partir dos processos de subjetivação, os fluxos, os devires e linhas estratégicas de existência podem ser conectados introduzindo nos modos de vida possibilidades para além dos controles, das normas, da lei, da moral, constituindo uma espécie de vida em potencial.

Portanto, os processos de subjetivação enredam-se pelo agenciamento dos desejos e a construção das identidades que serão sempre provisórias, cambiantes e contingentes. São processos circunstanciais que se agenciam constantemente em criações, invenções de si e todas as possibilidades de refazer-se. A criação é desejo em potencial, pois desejamos a vida, desejamos fazer da própria vida processos e não produtos.

O desejo produz-se a partir do fluxo constante, do movimento que nunca cessa, dos agenciamentos micropolíticos que acontecem a partir dessa reterritorialização e das conexões maquínicas que constituem através dos prazeres, das homossocialidades desejantes que sacodem, desestruturam e escancaram um modo de vida potente e que se produz nas próprias relações, nos processos de subjetivação. Tudo aqui é processo, tudo aqui é produção. Nem meio, nem fim. Efetivação de modos de vida queer que se inscrevem na diferença, nas multidões, no diverso, na multiplicidade e nas inúmeras formas de experimentação dos prazeres e dessa sexualidade desejante.

\section{REFERÊNCIAS}

BRAZ, Camilo Albuquerque. Provocações Queer à "Cultura LGBT". In: Oliveira Assis, Susana Bornéo Funck (organizadoras). Políticas e Fronteiras/Desafios Feministas. Ed. Copiart, 2014.

DELEUZE, Gilles. Nietzsche e a filosofia. Trad. de António M. Magalhães. Porto: RésEditora, 2001.

DELEUZE, Gilles. Conversações. Tradução de Peter Pál Pelbart. São Paulo: Ed.34, 1992.

DELEUZE, Gilles. O abecedário de Gilles Deleuze. Entrevista transcrita do ano de 1988.

DELEUZE, Gilles; GUATTARI, Félix. 0 anti-Édipo capitalismo e esquizofrenia. São Paulo: Ed.34, 2010. 
DELEUZE, Gilles; GUATTARI, Félix. Mil platôs capitalismo e esquizofrenia vol.5.

Tradução de Peter Pál Pelbart e Janice Caiafa. São Paulo: Ed.34, 1997.

DERRIDA, Jacques. Margens da Filosofia.Tradução Joaquim Torres Costa, António M. Magalhães. Campinas, SP: Papirus, 1991.

DERRIDA, Jacques. A escritura e a diferença. Tradução Maria Beatriz Marques Nizza, Pedro Leite Lopes e Pérola de Carvalho. São Paulo: Perspectiva, 2002.

DERRIDA, Jacques. Gramatologia. Tradução de Miriam Chnaiderman e Renato Janine Ribeiro. São Paulo: Perspectiva, 2004.

FOUCAULT, Michel. O anti-Édipo: introdução a uma vida não fascista. In: Cadernos de Subjetividade / Núcleo de Estudos e Pesquisas da Subjetividade do Programa de Estudos Pós-Graduados em Psicologia Clínica da PUC-SP. - v. 1, n. 1 (1993) - São Paulo, 1993 [páginas 197 a 200].

LARRAURI, Maite. O desejo segundo Gilles Deleuze. Tradução de Sérgio Rocha Brito Marques. São Paulo: Ciranda Cultural, 2009.

LIMA, Fátima. É possível um estado que abarque a multidão queer? Notas para pensar as multiplicidades na biopolítica contemporânea. In: Revista Periódicus de Estudos Indisciplinares em Gêneros e Sexualidades. UFBA, v.1, oํ1, 2014.

LIMA, Fátima. Corpos, gêneros, sexualidade: políticas de subjetivação; textos reunidos. $2^{\underline{a}}$ ed. Porto Alegre: Rede UNIDA, 2014.

LIMA, FÁTIMA; BORBA, Rodrigo. Sobre(des)aprendizagens e multidões queer:Rizomas, multiplicidades e a política menor. In: Alves, D. (org.), Gênero e Diversidade na Escola. Rio de Janeiro, 2014.

LOURO, Guacira Lopes. Um corpo estranho: ensaios sobre sexualidade e teoria queer. $1^{\underline{a}}$ ed. Belo Horizonte: Autêntica, 2008.

LOURO, Guacira Lopes; et al .O corpo educado. pedagogias da sexualidade. Traduções: Tomaz Tadeu da Silva. Belo Horizonte: $2^{\mathrm{a}} e d$, Autêntica, 2000.

MISKOLCI, R. A teoria queer e a questão das diferenças: por uma analítica da normalização. In: CONGRESSO DE LEITURA NO BRASIL, (COLE) 16, 2007, Campinas. Anais... Campinas: ALB Associação de Leitura do Brasil, v. 1. p. 1-19. 2007.

NIETZSCHE, Friedrich Wilhelm. O nascimento da tragédia, ou Helenismo e pessimismo. São Paulo: Companhia das letras, 1992.

NIETZSCHE, Friedrich Wilhelm. A visão dionisíaca do mundo e outros textos de juventude. São Paulo: Martins Fontes, 2005.

PRECIADO, Paul. Multidões queer: notas para uma política dos "anormais". In: Revista de Estudos Feministas, Florianópolis: janeiro-abril, 2011. 
PRECIADO, Paul. Manifesto contrassexual. Práticas subversivas de identidade sexual. Tradução: Maria Paula Gurgel Ribeiro. Editora: n-1 edições, 2014.

PETRONILIO, Paulo. Poesia: a máquina de guerra do pensamento. Texto Digital, Florianópolis. V.9, n.1, p.68-94, jan/jul.2013. Disponível em $<$ http://periodicos.mfsc.br/index.php/textodigital/article/view/18079288.2013v9 n1p68/25124.> Acesso em 10 set.2019.

PETRONILIO, Paulo. O signo como performance e performatividade da linguagem.In:Artefactum. Revista de Linguagem e Tecnologia. Ano VII, no2, 2015a.

SCHÉRER, René. Deleuze e a questão homossexual: uma via não platônica da verdade. In: Lugar Comum. nำ, Escola de comunicação da UFRJ, Jan- Abr, 1999.

\title{
NOTAS
}

\author{
Roberto Rodrigues \\ Mestre em Performances Culturais pela Universidade Federal de Goiás (UFG) \\ Professor Titular do Instituto Federal de Goiás, Campus Aparecida de Goiânia, Goiás \\ roberto.rodrigues@ifg.edu.br \\ (1) https://orcid.org/0000-0002-9862-561X
}

Endereço de correspondência do principal autor

Rua 10 Qd 66 A Lt 19, Vila Brasília, CEP 74911-090, Aparecida de Goiânia, Goiás

AGRADECIMENTOS
Agradecimento ao Dr. Paulo Petronilio.

CONTRIBUIÇÃO DE AUTORIA

Não se aplica

Concepção e elaboração do manuscrito: R. Rodrigues

Coleta de dados: R. Rodrigues

Análise de dados: R. Rodrigues

Discussão dos resultados: $R$. Rodrigues

Revisão e aprovação: R. Rodrigues

CONJUNTO DE DADOS DE PESQUISA

Todo o conjunto de dados que dá suporte aos resultados deste estudo foi publicado no próprio artigo.

FINANCIAMENTO

Não se aplica.

\section{CONSENTIMENTO DE USO DE IMAGEM}

Não se aplica

APROVAÇÃO DE COMITÊ DE ÉTICA EM PESQUISA

Não se aplica.

\section{CONFLITO DE INTERESSES}

Não se aplica.

LICENÇA DE USO - uso exclusivo da revista

Os autores cedem à Revista Internacional Interdisciplinar INTERthesis os direitos exclusivos de primeira publicação, com o trabalho simultaneamente licenciado sob a Licença Creative Commons Attribution (CC BY) 4.0 International. Estra licença permite que terceiros remixem, adaptem e criem a partir do trabalho publicado, atribuindo o devido crédito de autoria e publicação inicial neste periódico. Os autores têm autorização para assumir contratos adicionais separadamente, para distribuição não exclusiva da versão do trabalho publicada neste periódico (ex.: publicar em 
repositório institucional, em site pessoal, publicar uma tradução, ou como capítulo de livro), com reconhecimento de autoria e publicação inicial neste periódico.

PUBLISHER - uso exclusivo da revista

Universidade Federal de Santa Catarina. Programa de Pós-graduação Interdisciplinar em Ciências Humanas. Publicação no Portal de Periódicos UFSC. As ideias expressadas neste artigo são de responsabilidade de seus autores, não representando, necessariamente, a opinião dos editores ou da universidade.

EDITORES - uso exclusivo da revista

Javier Ignacio Vernal, Silmara Cimbalista e Selvino José Assmann (In Memoriam).

EDITOR ASSISTENTE: Eixo temático: (Re)discutindo sexualidade: corpo, prazer e desejo em tempos conservadores

Luiz Barp

HISTÓRICO - uso exclusivo da revista

Recebido em: 07-05-2020 - Aprovado em: 22-04-2021 - Publicado em: 30-04-2021 